\title{
Contribuições da Técnica de Ensino Brainstorming: Uma Experiência com Estudantes de uma Escola Estadual de Alta Floresta-MT
}

\author{
Marilaine de Castro Pereira Marques ${ }^{1}$; Mariana Emídio Oliveira Ribeiro²; Aparecida Garcia Pacheco Gabriel ${ }^{3}$; \\ Sidney da Silva Chaves ${ }^{4}$; Marlize Reffatti Zinelli ${ }^{5}$; Marcelino de Jesus ${ }^{6}$
}

\begin{abstract}
Resumo: Os objetivos do trabalho desenvolvido foram levar os alunos de $1^{\circ}$ Ano do Ensino Médio de uma Escola Estadual de Alta Floresta a: identificar característicos dos sistemas vivos e princípios da organização da vida; entender a definição de vida e o abordo como questões que envolvem princípios éticos, filosóficos, jurídicos, científicos e religiosos, utilizando a técnica de brainstorming. A escola onde se desenvolveu as práticas pedagógicas está situada em um bairro popular de Alta Floresta. As atividades foram realizadas em 04 aulas, ministradas no mês de março de 2017. Como resultado positivo pode se destacar: a manifestação de análises críticas, fundamentadas nos estudos sobre o assunto abordado; a capacidade que alguns demonstraram de se posicionar e também de ouvir os posicionamentos dos colegas; a capacidade de rever conceitos e justificar tal revisão; a troca de experiências; e a animação dos estudantes frente às proposições. Quanto aos desafios encontrados destacaram-se a necessidade de fazer muitas pausas para chamar atenção dos que estavam com conversas paralelas, ou que, não respeitavam a vez do colega falar, interrompendo-o antes que terminasse de proferir sua opinião. Também teve os que ficavam brincando e pedindo para sair da sala, seguidamente, o que exigiu muito empenho para trazer todos para a discussão. Alguns participaram mais, outros menos, mas de forma geral, a maioria opinou sobre o assunto.
\end{abstract}

Palavras-chave: Técnica de Ensino. Aprendizagem Ativa. Alfabetização Científica.

\section{Contributions of the Brainstorming Teaching Technique: An Experience With Students of Alta Floresta State School located at Mato Grosso}

\begin{abstract}
The objectives of the work were to bring the students of the 1st Year of High School of a State School of Alta Floresta to: identifying characteristics of living systems and principles of life organization; to understand the definition of life and to approach it as questions involving ethical, philosophical, juridical, scientific and religious principles, using the technique of brainstorming. The school where the pedagogical practices were developed is located in a popular neighborhood of Alta Floresta. The activities were carried out in 04 classes, given in the month of march, 2017. As a positive result can be highlighted: the manifestation of critical analysis, based on studies on the subject addressed; the ability of some to position themselves and also to listen to colleagues' positions; the ability to review concepts and justify such a review; the exchange of experiences; and the animation of the students in front of the propositions. As for the challenges encountered, there was a need to make many pauses in order to draw attention to those who were in parallel conversations, or who did not respect the turn of the colleague, interrupting him before he finished speaking. There were also those who kept joking and asking to leave the room, which required a lot of effort to bring everyone into the discussion. Some participated more, others less, but in general, most opined on the subject.
\end{abstract}

Keywords: Teaching Technique. Active Learning. Scientific Literacy.

\footnotetext{
${ }^{1}$ Mestre em Educação pela Universidade Federal do Mato Grosso UFMT. Professora da Faculdade de Alta Floresta (FAF); Professora das Escolas Estaduais 19 de Maio e Dom Bosco em Alta Floresta-MT. <marilainecastro@ hotmail.com>.

${ }^{2}$ Mestranda do Programa de Pós Graduação em Ambiente e Desenvolvimento (PPGAD) da Universidade do Vale do Taquari UNIVATES. Professora da Escola Técnica Estadual (ETE) e da Faculdade de Direito de Alta Floresta - FADAF e Faculdade de Alta Floresta-FAF, <mariana_meo@hotmail.com>.

${ }^{3}$ Mestranda em PPGEnsino - Univates. Bolsista Taxista (PROSUP - CAPES). Atualmente é docente permanente na Faculdade de Alta Floresta - FAF. psicopacheco_1@ @hotmail.com

${ }^{4}$ Mestrando em Educação pelo Instituto Educação Superior do Alto Araguaia - MT (IESA) conveniado pela Universidade Estácio de Sá (RJ) e Professor da Rede Estadual de Ensino de Mato Grosso e das Faculdades de Alta Floresta(FAF/FADAF). chaves_sidney@ hotmail.com

${ }^{5}$ Mestre em Ciências Ambientais e Desenvolvimento Sustentável pela UuniversidadeTécnica de Comercialización y Desarrollo - UTCD (Universidad de Asunción-Paraguay) e Professora da Escola Técnica Estadual (ETE) e da Faculdade de Direito de Alta Floresta - FADAF. <lize.zinelli@outlook.com.br>

${ }^{6}$ Mestrando em Educação pelo Instituto Educação Superior do Alto Araguaia - MT (IESA) conveniado pela Universidade Estácio de Sá (RJ) e Professor da Escola Técnica Estadual (ETE) e das Faculdades de Alta Floresta(FAF/FADAF).
} 


\section{Introdução}

O professor é um gestor de aprendizagens e como tal precisa ter clareza dos objetivos a serem alcançados com os estudantes, para obter êxito na complexa tarefa de educar. As técnicas utilizadas pelo professor como instrumento colaborativo das diversas situações de aprendizagens constituem um dos aspectos indispensáveis para a eficiência do processo.

Masseto (2003, p. 86) recorrendo ao Dicionário Larousse Cultural esclarece que técnica “é o conjunto de recursos e meios materiais utilizados na confecção de uma arte". O mesmo autor acrescenta que no caso do professor, a arte a ser realizada é a docência. No exercício da docência o referido profissional necessita de saberes que o auxilie nas tomadas de decisões, incluindo a capacidade de selecionar as técnicas mais apropriadas para as diversas situações educativas a serem propostas.

Cada turma, sujeitos e finalidades do fenômeno intitulado ensino-aprendizagem requerem técnicas específicas às suas particularidades, logo, a capacidade estratégica do docente para planejar suas práticas pedagógicas é um dos fatores preponderantes, para se alcançar resultados exitosos. A qualidade da formação do professor vai influencia muito a decisão desse profissional. Para uma atuação coerente com as demandas de seu tempo, este precisa estar constantemente em formação e atento às tendências da atualidade.

Existe uma diversidade de técnicas que podem ser utilizadas e o professor deve diversificar seu repertório, pois uma técnica por melhor que seja, quando repetida muitas vezes com o mesmo público faz com as aulas tornem-se rotineiras. A necessidade de diversificar as técnicas, também se justifica pelo fato dos estudantes precisarem desenvolver múltiplas capacidades. Considerando que cada uma das técnicas tem suas potencialidades e suas limitações, cabe ao professor selecioná-las considerando esses aspectos.

Quando o professor leva em conta essas perspectivas terá maior chance de motivar seus alunos e mantê-los envolvidos na proposta educativa, com vistas a aprendizagem significativa. Masseto (2003, p. 88) destaca que a variação de técnicas possibilita aos professores atenderem as diferenças individuas dos alunos, visto que alguns aprendem melhor ouvindo, outros debatendo e ainda outros aprender mais em atividades individuais ou 
coletivas. A variação de técnicas também beneficia o professor, tornando seu trabalho dinâmico, desafiador e criativo.

Os meios que o professor utiliza para favorecer a aprendizagem dos estudantes recebe o nome de estratégia. Para Masseto (20103, p. 86) "estratégia é a arte de decidir sobre um conjunto de disposições que favorecem o alcance dos objetivos educacionais". Por exemplo: que recursos e técnicas utilizar, como organizar as carteiras, que questionamentos fazer, em que sequência desenvolver as atividades, que fontes de pesquisas indicar aos estudantes, entre outras.

Os objetivos do trabalho desenvolvido com os alunos de $1^{\circ}$ Ano do Ensino Médio de uma Escola Estadual de Alta Floresta foram: Identificar característicos dos sistemas vivos e princípios da organização da vida que a torna um fenômeno único e objeto de estudo [...], do desenvolvimento da Biologia como campo do conhecimento (BRASIL, 2016, p. 621); Entender a definição de vida e o abordo como questões que envolvem princípios éticos, filosóficos, jurídicos, científicos e religiosos, utilizando a técnica de brainstorming.

A docência é uma profissão desafiadora, pois exige de seus profissionais capacidades para organizar situações de aprendizagens que possibilitem aos estudantes desenvolver as aprendizagens fundamentais para viverem com sucesso em cada tempo da existência humana. $\mathrm{Na}$ atualidade tais aprendizagens dizem respeito ao exercício da cidadania e ao o mundo do trabalho, conforme estabelece a Lei de Diretrizes e Bases da Educação Nacional N. 9394/96 (LDB).

Para se obter êxito em suas funções os docentes dependem de muitos conhecimentos. Para Tardif (2012) esses conhecimentos são oriundos da área de atuação, da didática e da experiência. Esse conjunto de conhecimentos influenciam as estratégias de atuação profissional. Como estrategistas de situações de aprendizagens, selecionam materiais, técnicas para organizar espaços e tempos formativos. A divulgação dos saberes e das experiências dos docentes ainda são tímidas se comparadas a grande ceara de produções no campo do processo ensino-aprendizagem, de autoria de especialistas que não têm conhecimento prático das suas proposições.

O trabalho desenvolvido com os estudantes do $1^{\circ}$ Ano do Ensino Médio de uma Escola Estadual de Alta Floresta, com o uso das técnicas de tempestade de ideias ou brainstorming, busca de informações em fontes variadas, debates, estudos dirigidos, 
socialização de produções e análise crítica sobre fatos a partir de uma referência de estudoforam de relevância para: se ampliar conhecimentos acerca das técnicas de ensino evidenciadas; e para motivar outros profissionais da educação a divulgarem suas produções.

\section{Métodos de Pesquisa}

A escola onde se desenvolveu as práticas pedagógicas com estudantes do $1^{\circ}$ Ano do Ensino Médio está situada em um bairro popular de Alta Floresta. Essa unidade de ensino recebe alunos também de outros bairros urbanos e também do campo. Os estudantes - na maioria das vezes - são filhos de trabalhadores assalariados que atuam no comércio local e em repartições públicas; alguns pais desempenham funções diversas, tais como empregadas doméstica, pedreiros. Alguns alunos apresentam dificuldades para cumprir normas sociais básicas de boa convivência, inerentes ao respeito, colaboração e ao vocabulário.

As atividades foram realizadas em 04 aulas, ministradas no mês de março de 2017. Os recursos didáticos utilizados foram: o quadro branco, livro didático de José Mariano Amabis e Gilberto Rodrigues Martho (2013); textos complementares de livro e revistas; e vídeos que os estudantes buscaram na internet sobre o assunto trabalhado.

Os estudantes realizaram atividades orais e escritas, nas quais tiveram que exercitar suas capacidades de leitura, escrita, interpretação, exposição e oralidade, de forma individual e em grupos. Também foram instigados a participarem de todas as etapas da experiência pedagógica e realizar o registro das mesmas.Para desenvolver os trabalhos se utilizou atécnica de ensino intitulada de brainstorming,

De acordo com Masseto (2003) tempestade cerebral ou braistorming trata-se de uma técnica que permite o desenvolvimento da criatividade e a produção de uma grande quantidade de ideias em um curto espaço de tempo. Nessa técnica apresenta-se um tema para os estudantes e pede que os mesmos verbalizem o que entendem sobre o referido tema sem preocupação com o certo ou errado, ou seja, com plena liberdade. O professor registra no quadro as ideias dos estudantes. Depois de um tempo determinado, o professor faz interferência para que os participantes percebam que algumas ideias podem ser agrupadas e 
que outras podem ser eliminadas. Dessa forma, professor e estudantes constroem conceitos com as concepções que foram apresentadas no processo.

\section{Resultados e Discussões}

Menegolla e San'Tanna (2010) esclarecem que seleção e organização de procedimentos são formas de atuação dos educandos e educadores em sala de aula, para alcançar os objetivos educacionais. Nesse processo, os educadores escolhem procedimentos, métodos, técnicas e modalidades de ensino, com o propósito de favorecer a aprendizagem. Com a mesma finalidade, escolhem os recursos que podem ser mais adequados alcançar os objetivos e para despertar o interesse dos educandos, com suas complexidades.

Essa não é uma tarefa simples, pois, o que é interessante para um grupo de alunos pode não ser para outros. A ação educativa é carregada de incertezas e desafios. Cada público, cada experiência é ímpar e como tal exige do educador uma reflexão atenta das variáveis e dos fenômenos do contexto escolar. O educador também é uma unidade complexa, com seu potencial e limitação, que planeja, realiza, avalia os resultados dos trabalhos, pontuando os avanços e as necessidades de retomadas.

Os princípios, os fundamentos e objetivos de cada área do currículo escolar, estão explicitados em documentos oficiais dos sistemas de ensino, para orientar as escolas e professores no desenvolvimento de suas responsabilidades para um mundo pós-moderno. Dentre esses documentos, destacam-se as Leis da educação, os planos de educação, as orientações e diretrizes curriculares, nos âmbitos nacional, estadual e municipal.

As Orientações Curriculares de Ciências da Natureza de Mato Grosso (OCs) esclarecem que o objeto de estudo das Ciências da Natureza é o fenômeno vida em toda sua diversidade de manifestações (MATO GROSSO, 2012, p. 9). Por sua vez, a Unidade 1 de Biologia proposta pela Base Nacional Comum Curricular diz respeito à vida como fenômeno e seu estudo. No Eixo Conhecimento Conceitual proposto pela mesma Base está o objetivo introdutório da Unidade em questão, a saber:

Identificar os processos característicos dos sistemas vivos e princípios da organização da vida que a tornam um fenômeno único e objeto de estudo de uma 
ciência unificada no contexto da história do desenvolvimento da Biologia como campo do conhecimento (BRASIL, 2016, p. 621).

Para alcançar esse objetivo com uma turma de $1^{\circ}$ Ano do Ensino Médio, de uma Escola Estadual de Alta Floresta abordou-se o conteúdo características dos seres vivos ${ }^{2}$ por meio da técnica brainstorming, utilizando o questionamento: Quando inicia a vida?

As respostas apresentadas por eles foram dispostas no quadro branco da sala de aula. As referidas respostas estão explicitadas no Quadro 1, no qual também estão apresentadas o agrupamento das respostas com o mesmo sentido.

Quadro 1: Respostas dos estudantes sobre quando inicia a vida humana

\begin{tabular}{|c|c|c|}
\hline Ordem & Respostas dos estudantes & $\begin{array}{l}\text { Reorganização das respostas } \\
\text { Com o auxílio do livro didático. }\end{array}$ \\
\hline 01 & $\begin{array}{l}\text { Desde quando o ser está na barriga da mãe } \\
\text { (resposta de } 05 \text { estudantes); }\end{array}$ & \multirow{3}{*}{$\begin{array}{l}\text { Agrupamento das repostas } 01,02 \text { e } \\
03 \text {; } \\
\text { A partir do momento que o óvulo é } \\
\text { fecundado pelo espermatozoide. }\end{array}$} \\
\hline 02 & $\begin{array}{l}\text { No instante que a mãe engravida (resposta de } 04 \\
\text { estudantes); }\end{array}$ & \\
\hline 03 & $\begin{array}{l}\text { A partir do momento que o espermatozóide } \\
\text { fecunda ó óvulo (resposta de } 06 \text { estudantes); }\end{array}$ & \\
\hline 04 & $\begin{array}{l}\text { Quando começa a respirar (resposta de } 3 \\
\text { estudantes); }\end{array}$ & \multirow{4}{*}{$\begin{array}{l}\text { Respostas descartadas pelos } \\
\text { estudantes após os questionamentos e } \\
\text { explanaçãoda professora. }\end{array}$} \\
\hline 05 & $\begin{array}{l}\text { A vida inicia quando o coração começa os } \\
\text { batimentos (resposta de } 2 \text { estudantes) }\end{array}$ & \\
\hline 06 & Quando nasce (resposta de 04 estudantes); & \\
\hline 07 & $\begin{array}{l}\text { Quando o corpo do ser vivo está formado } \\
\text { (resposta de } 4 \text { estudantes); }\end{array}$ & \\
\hline
\end{tabular}

Fonte: Dados coletados pelos autores Marilaine de Castro Pereira Marques; Mariana Emidio Oliveira Ribeiro; Aparecida Garcia Pacheco Gabriel; Sidney da Silva Chaves; Marlize Reffatti Zinelli; Marcelino de Jesus, no ano de 2017.

Após anotar a apresentação dos estudantes no quadro branco, iniciou-se um diálogo com os educandos, por meio de questionamentos para que os mesmos percebessem que algumas repostas poderiam ser agrupadas.

- Desde quando o novo ser está na barriga da mãe? Um dos educandos respondeu: "Quando inicia a gravidez". A partir dessa resposta fez-se um novo questionamento: - E quando podemos dizer que iniciou a gravidez? Outro estudante respondeu: - "Quando o gameta masculino se funde com o gameta feminino". Após essas repostas, perguntou-se aos demais estudantes se concordavam ou se tinham outra opinião. A maioria se posicionou

\footnotetext{
${ }^{2}$ Características dos seres vivos: organização celular, metabolismo, reação, movimento e crescimento, reprodução e evolução; vida, e aborto (AMABIS; MARTHO, 2013).
} 
destacando que concordava com as respostas em voga. Ao serem questionados se era possível agrupar as três respostas debatidas, os estudantes emitiram parecer favorável.

Continuando as discussões, pediu-se aos alunos que se lembrassem das características dos seres vivos e a definição de vida proposta pelos Chilenos Francisco Varella e Humberto Maturana $^{3}$, estudados em aulas anteriores, para justificarem o início da vida. Tais estudos foram realizados com o livro didático de Amabis e Martho (2013) autores da obra Biologia em Contexto - livro didático do Ensino Médio - utilizaram o conceito dos referidos biólogos em um texto intitulado de "O que caracteriza a Vida".

Após esse lembrete, alguns estudantes ressaltaram: - "O novo ser tem organização celular e metabolismo; - tem capacidade de crescer; um dia poderá reproduzir; também tem capacidade de evoluir". Outros concordaram com o que foi apresentado e ainda outros, não se posicionaram, sendo esses últimos a minoria.

Para complementar as discussões destacou-se algumas questões do desenvolvimento fetal, entre elas que: o coração do embrião inicia os batimentos no começo do terceiro mês de gestação; que o pulmão do feto amadurece no final da gestação; que o amadurecimento de todos os órgãos do feto ocorre no terceiro trimestre de gestão e que quando ele nasce é porque já passou por um logo processo de formação que o possibilitará a viver fora do corpo da mãe.

Quando os estudantes emitiam resposta fundamentada com coerência, eram elogiados e os demais eram estimulados a intensificarem suas participações. Para continuar os trabalhos, os estudantes foram chamados a discutir as demais respostas oferecidas por eles. Para tanto, foi perguntado:

- Se vocês concordaram que a vida inicia quando ocorre a fecundação do óvulo pelo espermatozóide e que a partir daí se tem um ser vivo, então o que fazer com as demais repostas? A esse questionamento, os estudantes deram as seguintes respostas:

- "Estão erradas; - é isso aí professora; - agora que a senhora chamou atenção para algumas coisas, verificamos que a vida inicia antes do corpo do ser vivo estar formado e antes dele nascer; - pode cancelar as outras respostas professora, elas estão erradas". Em resumo os educandos que se posicionaram afirmaram que as demais questões que estavam contraditórias em relação as três primeira que foram agrupadas no quadro 1, poderiam ser desconsideradas.

\footnotetext{
${ }^{3} \mathrm{O}$ conceito de vida proposto por Varella e Maturana esclarece que vida trata-se de um sistema autopoiético, ou seja, que se autoconstrói e se automantém, que tem base aquosa, limites lipoproteicos, metabolismo de carbono, replicação por meio de ácidos nucléicos, e regulação protéica. 
Uma das estudantes comentou: - Professora, quando a senhora pediu para definir o início da vida, parecia que era uma questão simples; mas, conforme fomos debatendo, fui percebendo que é complexa. Aproveitando esse relato, perguntou-se a turma se outros tiveram essa percepção. A maioria respondeu afirmativamente.

As atividades que demandam Julgar, classificar, dar opinião analisar (categorizar e comprar, distinguir entre fato e opinião) auxiliam os educandos a aprimorar suas capacidades de interpretar evidencias e tirar conclusões (DIGBY, 2016).

Pelo exposto, as respostas proferidas pelos educandos foram valorizadas e utilizadas para reafirmar conceitos, apontar aspectos para reflexão, ou para questionar equívocos. As mediações e complementos foram realizados conforme as necessidades emergentes. As práticas em voga se mostraram adequadas para os objetivos traçados; cada estudante aproveitou a experiência de forma particular, pois cada ser é único, contudo, ainda que não ao mesmo tempo, conseguiu-se envolver os alunos.

Sabe-se que a prática docente exige a diversificação e a adequação de técnicas de estudo, conforme o perfil do público atendido e que o referido trabalho é desafiador e incerto. Para essa iniciativa, enfrentou-se várias dificuldades para promover os debates, pois alguns alunos da turma têm dificuldade em obedecer normas e acordos pedagógicos. Foi necessário muitas paradas para chamar atenção dos que estavam com conversas paralelas, ou que, não respeitavam a vez do colega falar, interrompendo-o antes que terminasse de proferir sua opinião.

Também teve os que ficavam brincando e pedindo para sai da sala - tomar água e ir ao banheiro - seguidamente, o que exigiu muito empenho para trazer todos para a discussão. Alguns participaram mais, outros menos, mas de forma geral, a maioria opinou sobre o assunto. Vale ressaltar, que promover trabalhos de debates no qual o aluno precisa refletir sobre estudados anteriores e utilizá-los para resolver situações desafiadoras, auxilia no desenvolvimento de capacidades indispensáveis ao letramento científico e a vivência cidadã.

A possibilidade de situações emergentes não consideradas no momento de planejar podem trazer situações embaraçosas que o profissional tem que resolver inusitadamente para continuar seu trabalho. Mesmo que se tenha um plano B, este também pode se mostrar inadequado para alguns casos, o que traz certamente tensão ao profissional. Ou seja, nenhum 
planejamento é garantia de sucesso absoluto. Algumas coisas acontecem conforme foi planejado e outras não, no entanto é mister planejar.

Desenvolver atividades na perspectiva dos métodos ativos requer a organização de materiais, técnicas, espaço e tempo, voltados para o perfil de um determinado público, colocando-os como protagonistas no processo. Lecionar com esse intuito é mais complexo que trabalhar com situações em que os educando participam passivamente. Essa perspectiva exige do docente esforço e capacidade de lidar com o inesperado, de forma mais contundente.

Mesmo enfrentando as dificuldades para desenvolver a prática supracitada, no que se refere a atitude de alguns alunos que precisam aprimorar suas capacidades de respeitar regras, entende-se que será participando desse tipo de atividade que os mesmos poderão alcançar melhorias referentes aos conhecimentos conceituais, procedimentais e atitudinais.

Como resultado positivo oriundo do trabalho sobre: quando inicia a vida e o posicionamento dos estudantes sobre essa questão, pode se destacar: a manifestação de análise crítica, fundamentada nos estudos sobre o assunto abordado; a capacidade que alguns demonstraram de se posicionar e também de ouvir os posicionamentos dos colegas; a capacidade de rever conceitos e justificar tal revisão; a troca de experiências; bem como a animação dos estudantes frente as proposições da professora.

\section{Considerações Finais}

Com o desenvolvimento dos trabalhos inerentes a quando inicia a vida e o posicionamento dos estudantes sobre essa questão, por meio de técnicas e métodos ativos de estudos (tempestade cerebral ou brainstorming obteve-se resultados positivos e também se deparou com algumas dificuldades.

O trabalho foi desenvolvido com uma turma do $1^{\circ}$ Ano do Ensino Médio, no qual alguns alunos da turma têm dificuldades em obedecer normas e acordos pedagógicos. Assim, foi necessário fazer muitas pausas para chamar atenção dos que estavam com conversas paralelas, ou que, não respeitavam a vez do colega falar, interrompendo-o antes que terminasse de proferir sua opinião. Também teve os que ficavam brincando e pedindo para sair da sala, para tomar água ou ir ao banheiro seguidamente, o que exigiu muito empenho 
para trazer todos para a discussão. Alguns participaram mais, outros menos, mas de forma geral, uma boa participação.

Como resultado positivo oriundo do trabalho pode se destacar: a manifestação de análise crítica, fundamentada nos estudos sobre o assunto abordado; a capacidade que alguns demonstraram de se posicionar e ouvir os posicionamentos dos colegas; a capacidade de rever conceitos e justificar tal revisão; a troca de experiências; a animação dos estudantes frente às proposições; bem como, o envolvimento da maioria dos educandos.

Desenvolver atividades com métodos ativos requer a organização de materiais, técnicas, espaço e tempo, voltados para o perfil de um determinado público, colocando-os como protagonistas no processo. Lecionar com esse intuito é mais complexo que trabalhar com situações em que os educandos participam passivamente. A perspectiva dos métodos ativos exige do docente esforço e capacidade de lidar com o inesperado, de forma mais contundente.

Mesmo enfrentando as dificuldades para desenvolver a prática supracitada, no que se refere a atitude de alguns alunos que precisam aprimorar suas capacidades de respeitar regras, entende-se que será participando desse tipo de atividade que os mesmos poderão alcançar melhorias referentes aos conhecimentos conceituais, procedimentais e atitudinais.

Vale ressaltar, que promover trabalhos no qual o aluno precisa refletir sobre estudados anteriores e utilizá-los para resolver situações desafiadoras, auxilia no desenvolvimento de capacidades indispensáveis ao letramento científico e a vivência cidadã.

\section{Referências}

AMABIS, José Mariano; MARTHO, Gilberto Rodriguês. Biologia em Contexto. Biologia Ensino Médio. São Paulo: Moderna, 2013.

BRASIL. Ministério da Educação e do Desporto. Base Nacional Curricular Comum. Brasília: MEC, 2013.

BRASIL (1996). Lei no 9394, de 20/12/96. Lei de Diretrizes e Bases da Educação Nacional. Diário Oficial da União, ano CXXXIV, No 248, 23/12/96, pp.27.833-27.841. (Brasil). $\mathrm{N}^{\circ}$ 9394/96. 
Id on Line Revista Multidisciplinar e de Psicoloqia

Id on Line Multidisciplinary and Psycology Journal

DIGBY, Rebeca; COLLIER, Chris. Desenvolvendo as habilidades de pensamento e aprendizagem em Ciências. In: Aprendizagem Ativa: nos anos iniciais do ensino fundamental. AnitraNickery. Tradução de Henrique de Vieira Guerra. Porto Alegre: Penso, 2016.

MASSETO, Marcos Tarciso. Competências Pedagógicas do Professor Universitário. São Paulo: Summus, 2003.

MATO GROSSO. Secretaria de Educação de Mato Grosso. Educação Básica. Orientações Curriculares de Mato Grosso - Área de Ciências da Natureza e Matemática. Cuiabá: Defanti, 2012.

MENEGOLlA, Maximiliano; SANT'ANNA, Ilza Martins. Por que planejar?:currículo, área, aula. Petrópolis, RJ: Vozes, 2010.

TARDIF, M. Saberes docentes e formação profissional. $3^{\text {a }}$.ed. Petrópolis: Vozes, 2012.

Como citar este artigo (Formato ABNT):

MARQUES, marilaine de C.P.; RIBEIRO, mariana E.O.; GABRIEL, Aparecida G.P.; CHAVES, Sidney da S.; ZINELLI, marlize R.; JESUS, marcelino de. Contribuições da Técnica de Ensino Brainstorming: Uma Experiência com Estudantes de uma Escola Estadual de Alta Floresta-MT. Id on Line Revista Multidisciplinar e de Psicologia, 2017, vol.11, n.37, p. 318-328. ISSN: 1981-1179.

Recebido: 28.08.2017

Aceito: 30.08 .2017 